www.revistadyo.com

\title{
Organisational Innovation in Bureaucracies: An Impossible Mission?
}

Carlos F. Gómez Muñoz, Ana Moreno Romero

https://doi.org/10.37610/dyo.v0i74.602
Recibido: 12 de Enero de 2021

Aceptado: 1 de Marzo de 2021

\begin{abstract}
Organisational innovation can be one of the levers for implementing better management practices in the public sector. However, this innovation needs to be examined in the light of the complexity, as this is a main feature of public policies, as well as of the public sector organisations that deal with them. To address that complexity, this research uses the conceptual framework developed by Frédéric Laloux in his investigation about 'Teal' organisations, connecting it to the theoretical background on the application of complexity theory to organisation studies and public management.
\end{abstract}

The main goal of the research is then to identify and analyse, according to the 'Teal' organisations framework, experiences of organisational innovation in European public administrations. For this analysis, the organisational structure, human resources processes and daily practices (routines spread over the organisation incorporating values and policies) are examined, together with the conditions for the emergence of these initiatives, the key elements for their sustainability, and their effect on the performance of the organisation.

The research uses the case study as research strategy, identifying four cases where different forms of organisational innovation are being implemented: the Belgian Federal Public Service of Social Security, the Municipal Music Conservatory of Barcelona, the A.2 unit of the Executive Agency for Small and Medium-Sized Enterprises (EASME) of the European Commission and the European Court of Auditors.

Even though the sample of cases is too small to draw general conclusions, the findings show that innovation in organisational practices in the public sector is not only possible, but it is happening. By comparing these four cases, the research finds some common patterns that could be used as a reference by public sector practitioners concerned with introducing new ways of working in their organisations

\section{Palabras clave}

Organisational innovation; complexity theory; evolutionary organisations; Public Administration; public sector performance

\section{Introduction}

Over the last few decades, public services have been generally contested. Looking at ways of improving public sector performance, governments all over the world have adopted various reform initiatives with different approaches and results (Boyne, 2003). In his analysis of some of these initiatives, Boyne (2003) suggests that the most likely sources of public service improvement are extra resources and better management.

\footnotetext{
$凶 \quad$ Carlos F. Gómez Muñoz * cf.gomez@alumnos.upm.es

As one of the levers for implementing better management practices, organisational innovation can be a key element of the public sector reform and deserves to be further investigated. In that sense, the main goal of this research was precisely to identify and analyse experiences of organisational innovation in European public administrations and institutions, in order to understand their specific features and recognise practices that could be exploited for improving public sector performance. At the same time, it aimed to bring organisation science closer to public administration studies, two fields closely related at their origins, which have growingly diverged in the last decades (Vogel, 2014).

This organisational innovation, however, needs to be examined in the light of complexity. Complexity is an essential attribute of most policy issues today (OECD, 2017) and a core feature of public sector organisations, arising from their unique identities, institutional aspects, and values. The different roles they need to play as traditional bureaucracies focused on rationality and compliance with the law, providers of public services with quality and efficiency, and facilitators of collaboration networks with public and private stakeholders to respond to social challenges, add to this complexity (Gómez Muñoz and Serrano Calle, 2018). 
To address complexity in public organisations, this research used the conceptual framework developed by Laloux (2014) in his investigation about 'evolutionary-Teal organisations'. That is also one of the major contributions of the research, as there is hardly any reference to this framework in the literature (Wyrzykowska, 2019), and its application to the public sector is even scarcer.

\section{Theoretical background}

\subsection{Complexity theory in public management and organisation studies}

One of the approaches that is attracting more interest to cope with the challenges faced by the public sector is the application of the complexity theory to public management, although authors like Daneke (1990) already proposed, almost thirty years ago, to use concepts and ideas related to complexity and systems theory to improve the scientific status of public policy and administration studies.

The growing academic interest in how complexity theory could be used to understand and inform public policy and its complementarity with network governance and new public management theories is evidenced by the establishment in 2014 of two new journals: Journal on Policy and Complex Systems and Complexity, Governance and Networks (Eppel and Rhodes, 2018).

Some examples of the application of complexity theory to the public management and public administration fields can be found in the works of Klijn (2008), who explains how three main concepts of complex systems (dynamics, selforganisation and co-evolution) can be relevant for public administration research; Teisman, van Buuren and Gerrits (2009) who apply complexity theory to the study of systems and process of public governance; and Geyer and Cairney (2015), who use complexity theory to study public policy and its formulation.

It must be noted, however, that what is commonly known as complexity theory is in fact a collection of different theories. In that sense, Mitleton-Kelly (2003) advocates using the term 'complexity theories' instead, and distinguishes five main areas of research: (a) complex adaptive systems (CAS); (b) dissipative structures; (c) autopoiesis theory; (d) chaos theory; and (e) increasing returns and path dependence.

The concept of evolution appears closely linked to complexity theories, and plays a key role in CAS, where evolutionary forces are behind the notion of adaptation (Levin, 1998, 2003; Holland, 2006). In fact, evolutionary ideas, whether as part of complexity-based approaches or on their own account, have been long applied to social science, including public administration (Sementelli, 2007).
For example, evolutionary theory, combined with the original approach to systems theory developed in his Social Systems theory (Luhman, 1995), is the basis of Luhmann's conception of organisational change (Seidl and Mormann, 2015) However, this application is not free from controversy, as there are different conceptions on what evolution means in the social context; in that sense, a distinction must be made between 'evolutionist' approaches, which assume that change occurs through a sequence of ascending stages towards some type of 'telos' or end, and 'evolutionary' approaches, which exclude prior assumptions about the purpose of change and focus on the processes and mechanisms that drive evolution (Kerr, 2002).

Like public policy and administration studies, organisation science has also looked at complexity theory as a source for insights that could foster the theoretical development in the field, and complexity theories have been at the core of management thinking since the 1990s (Stenvall and Virtanen, 2017). According to Anderson (1990), "Since the opensystems view of organizations began to diffuse in the 1960s, complexity has been a central construct in the vocabulary of organization scientists". In that sense, in his proposal for a new approach to organisation science that could bring together the different competing paradigms, complexity theory was already one of the main elements considered by McKelvy (1997). Prior to that, Stacey (1995) encouraged the use of the framework of complexity, and in particular that of the CAS, to approach strategic change in organisations.

Among the different attempts to apply complexity theory to the study of organisations, two approaches must be mentioned: organisational cybernetics (Bohórquez Arévalo and Espinosa, 2015) and especially, due to the importance it concedes to evolution-related aspects, the 'complex evolving systems' (CES) approach of Mitleton-Kelly (2003) For this author, CES behaviour, distinctive of organisations, goes beyond CAS and is characterised by ten generic principles: (i) interconnectivity, (ii) interdependence, (iii) feedback, (iv) emergence, (v) self-organisation, (vi) exploration of the space of possibilities, (vii) co-evolution, (viii) history and path dependence, (ix) far-from-equilibrium state and (x) creation of a new order.

\subsection{Evolutionary -Teal organisations as Complex Evolving Systems}

Building on evolutionary concepts from other disciplines, Laloux (2014) provides an interpretative framework for examining organisational innovation. He considers that organisational paradigms have developed according to several stages, which he describes using colours, as shown in Table 1. These stages have been inspired by the levels in the Spiral Dynamics model introduced by Graves (1970) and further developed by Beck and Cowan (1996) but mainly on the adaptation made by Wilber of Spiral Dynamics to create his Integral Theory (2005). 


\begin{tabular}{|c|c|c|c|c|}
\hline Table 1 Organisational & Paradigm & Examples & Key breakthroughs & Guiding metaphor \\
\hline paradigms according to & & & & \\
\hline \multirow[t]{4}{*}{ Laloux (2014). } & Impulsive - Red & $\begin{array}{l}\text { Mafia, street gangs, tribal mi- } \\
\text { litias }\end{array}$ & $\begin{array}{l}\text { Division of labor, command au- } \\
\text { thority }\end{array}$ & Wolf pack \\
\hline & Conformist - Amber & $\begin{array}{l}\text { Catholic church, military, gov- } \\
\text { ernment agencies, public school } \\
\text { systems }\end{array}$ & Formal roles, processes & Army \\
\hline & Achievement - Orange & $\begin{array}{l}\text { Multinational companies, char- } \\
\text { ter schools }\end{array}$ & $\begin{array}{l}\text { Innovation, accountability, mer- } \\
\text { itocracy }\end{array}$ & Machine \\
\hline & Pluralistic-Green & Culture driven organisations & $\begin{array}{l}\text { Empowerment, values-driven } \\
\text { culture, stakeholder model }\end{array}$ & Family \\
\hline
\end{tabular}

For Laloux, 'evolutionary - Teal organisations', whose guiding metaphor is the living system, are the next step of organisational development, based on three organisational breakthroughs: (i) self-managed teams, (ii) wholeness and (iii) evolutionary purpose. It must be noted that, although Laloux uses the term 'evolutionary' here, according to the distinction highlighted above between 'evolutionist' and 'evolutionary' conceptions of change, it would be more appropriate to name Teal organisations as 'evolutionist', due to the ascending character of the stages identified in Laloux's framework.

Due to its self-management features, Teal organisations show close links to the 'Self-managing organisation' (SMO) concept proposed by Lee and Edmondson (2017), characterised by a radical and organisation-wide decentralisation of authority, supported by a formal system. However, even though self-management may be the most visible trait of Teal organisations, Laloux concedes equal importance to the wholeness and evolutionary purpose aspects, which are constantly expressed in the way Teal organisations behave.

According to Laloux, Teal organisations act as living beings, adapting to their environment thanks to the capabilities of their members for self-organising and selfmanaging in the pursuit of the goals that constitute their 'reason d'être'. Within the Teal paradigm, small groups of workers, who take over management functions and can adopt different roles according to the needs, replace traditional planning and control structures. Decisions are made through consultation processes with the participation of those involved, and coordination is achieved not through the traditional hierarchy, but through frequent communication with colleagues, exchange of knowledge, and engagement of employees with the mission and values.

Seen from the perspective of complexity, Teal organisations may be assimilated to CES, as their three key breakthroughs can be linked to the generic principles about CES behaviour proposed by Mitleton-Kelly (2003)
- Self-management is described by Laloux (2014) as "the key to operate effectively, even at a large scale, with a system based on peer relationships, without the need for either hierarchy or consensus". It can be related to the features of interconnectivity and interdependence, needed to support the peer relationships, and far-from-equilibrium state and creation of a new order, drivers of the changing organisational patterns and new ways of working.

- Wholeness is described by Laloux (2014) as "a consistent set of practices that invite us to reclaim our inner wholeness and bring all of who we are to work". It can be related to the exploration of the space of possibilities, as the recognition of spiritual and emotional aspects fosters the generation of variety needed to support adaptation. Also, it can connect to co-evolution, as personal, team and organisation development are perceived as going hand in hand in wholeness practices.

- $\quad$ Evolutionary purpose is described by Laloux (2014) in the following terms: "Teal Organizations are seen as having a life and a sense of direction of their own. Instead of trying to predict and control the future, members of the organization are invited to listen in and understand what the organization wants to become, what purpose it wants to serve". It can be related to feedback (regulation in opposition to control), emergence (as strategy emerges organically from daily operations) and history and path dependence (as the organisation trajectory conditions how it can evolve).

\section{Methods}

The research used the case study as research strategy, as it is particularly well-suited to new areas of investigation (Eisenhardt, 1989). Because the use of multiple cases supports the formulation of propositions more deeply based in empirical evidence, and leads to more parsimonious, robust and generalisable theories (Eisenhardt and Graebner, 2007), a multiple-case approach was chosen. 
Cases were selected according to theoretical sampling, by examining available information of organisational innovation in the European public sector and selecting those experiences more suitable for revealing common patterns and relationships. In order to support generalisation of findings, diversity was one of the main selection drivers, as the chosen cases correspond to public administrations belonging to different territorial levels: local, national, and European Union.

Hence, the research was based on a qualitative analysis of the secondary information available corresponding to four cases:

1. The Belgian Federal Public Service of Social Security (SPFSS) (Van Massenhove; European Commission, 2017; SPF Securité Sociale).

2. The Municipal Music Conservatory of Barcelona (Martí and Doncel Carrillo, 2018)

3. The A.2 unit of the Executive Agency for Small and Medium-Sized Enterprises (EASME) of the European Commission (De Bruin, Prieto Tovar and Pelland, 2017).

4. The European Court of Auditors (European Court of Auditors, 2015).

In the case of the Music Conservatory of Barcelona, EASME A.2 and the Court of Auditors, where access to primary sources was possible, secondary information was complemented with primary information obtained from interviews to relevant actors of both organisations directly involved in the implementation of organisational innovation practices.

\section{Results}

The four selected cases were analysed according to the model developed by Laloux (2014) when describing the features characterising Teal organisations. In that sense, the organisational structure, human resources processes and daily practices (routines spread over the organisation incorporating values and policies) were studied. Also, the research examined the conditions for the emergence of these initiatives, the key elements for their sustainability, and their effect on the performance of the organisation.

A description of each of the four studied cases is provided below, while main findings are summarised in Tables 2 to 6 .

\subsection{The Belgian Federal Public Service of Social Security}

Driven by a poor performance in handling citizens in need cases, and a bad reputation among new civil servants, the Federal Public Service of Social Security of Belgium, led by its Chairman Frank Van Massenhove, decided to implement a radical organisational change.

After some years of preparation, studying the interests and motivations of young generations, and analysing how the functions the organisation was responsible for were actually performed, SPFSS shifted to a new way of working, based on a culture of staff empowerment and trust, on 1st January 2009.

The starting point was moving from a performance assessment based on physical presence at the office to one based on results. Under the new framework, the expected results are currently specified by the management, and staff is given the freedom to decide on how best to achieve them, including how tasks must be distributed among team members. In defining these goals, the management is careful about setting realistic levels, providing enough room for coping with unforeseen events and workloads, and for implementing improvements and innovations.

This implied that every individual became able to organise his or her own work, including the decision about where to do it, which has led to most people choosing to work part of their week (up to 3 days) from home. As a consequence of this freedom given to employees, and the self-motivation culture that was promoted, the need for a management layer was reduced to just three managers for a staff of around seven hundred people. Decisions are now mostly made by the employees themselves, who are continuously involved in shaping the future of the organization, including the definition of its strategy.

The change was possible because of the determined bet of SPFSS for digitalisation, making the file to follow the worker, and not the other way round. To do so, the IT department was set the challenge to provide remote and secure access to SPFSS files and processes, at any time, from any place, and through any device.

The changes introduced by SPFSS had also an important effect on the office environment. Because most people preferred to work from home, the need for office space diminished significantly, so SPFSS was able to make great savings in running costs by moving to a new building with less office space. Moreover, the new office environment was not designed to contain individual offices, even for the managers, but to provide shared working spaces that foster calmness and creativity. 
The new way of working affected how meetings were conducted, as most of them became video based. The focus on results and not on presence helped to reduce the number of meetings, their duration, and the people attending them, as meetings are now expected to be called to discuss problems or opportunities, and not just as a means for the management to supervise the work.

In the implementation of the cultural change, SPFSS paid special attention to the recruitment process. As part of the Belgian Federal Government, SPFSS recruitment is made through the SELOR (Selection Office of the Belgian Federal Administration). However, under the new recruitment framework introduced in SPFSS, those candidates who have passed the SELOR selection process and wish to work in SPFSS must now hold several interviews with their future colleagues, where its fit with the culture of the organization is assessed. This helps to avoid recruitment mistakes, and to integrate the new recruits more easily into the organisation, as the colleagues that participated in their selection are more eager to provide them with the coaching and the support they need to be successful.

The cultural shift affected career development too, so that promotions now take into account the managerial profile of the candidate and not only his or her expertise, and bosses are evaluated by their subordinates. Also, when assessing next steps in the career path, those team members that are not able to find a position in accordance with their aspirations are asked if they want to leave and helped in their transition to a new job in case they decide to do so.

The new culture, management style, working practices and physical environment brought a substantial improvement in productivity. At the end of 2009, the first full year of transformation, SFPSS showed a productivity rise of $23 \%$, while the figures for the next two years, 2010 and 2011, showed also two-digits productivity increases $(11 \%$ and $15 \%$ respectively).

The transformation also affected very positively the perceived image of the organisation, which moved from being the least desired destination for new recruits in the civil service in 2002 (only $18 \%$ were willing to work there) to being the preferred destination in 2016 (with $93 \%$ of new recruits requesting to join the SPFSS).

\subsection{The Municipal Music Conservatory of Barcelona}

After more than a century of life, the Municipal Music Conservatory of Barcelona was, in early 2000s, going through an institutional crisis that led to the appointment of a new manager, David Martí.
In order to connect the institution to its historical roots of promoting the well-being of people through musical practice, Martí started opening the Conservatory to the citizenship through concerts, open trainings, collaborations with other organisations, transparency and other activities like the creation of a radio station.

This new orientation of treating music as a citizen's service was implemented by creating a more flexible and agile structure on top of the existing bureaucratic and hierarchical structure associated to the formal music teachings the Conservatory is legally obliged to deliver. Thanks to this parallel structure, the Conservatory is now able to perform activities addressed to the community, like open courses on music theory, instrument playing or musical culture, without interfering with the activities required for the delivery of the professional music teachings.

To support the practices associated with the new structure, Martí promoted the elaboration a Deontology code, created with the participation of the teachers, which includes the commitment of the teaching community of the Conservatory with society, and the principles, attitudes and values that should guide its activity.

This new way of working relies mainly on the voluntary collaboration of teachers and administrative staff, organised according to self-management principles, as they can choose the initiatives they want to be involved, and their roles in those initiatives are changing and flexible.

This self-management approach is also applied when organising training for the own Conservatory staff; whenever a small group of at least 3 people proposes to arrange for a training session, this is accepted and implemented.

In the case of teachers, self-management extends also to the organisation of their own working time. Apart from attending some fixed meetings required for running the activities linked to the professional music teachings, they enjoy flexible working times, with everyone respecting the others' agendas.

In order to foster this self-management attitude, the Conservatory adopted some initiatives to minimise signs of status associated to hierarchy, such as providing shared parking spaces to be used by everyone, instead of reserving them for the management.

Together with self-management, the Conservatory also worked on the wholeness dimension, offering frequent training on humanistic content like non-violent communication, or regular meditation practices conducted by external professionals. This was accompanied by measures to promote openness and transparency, such as installing crystal walls and doors. 
Being a municipal institution and therefore subject to the administrative regulations and procedures set for the public sector, one of the main challenges the Conservatory faced was to implement the new way of working without breaking the rules. Although it was not always possible to introduce all the desired changes, the Conservatory was able at least to modify the recruitment process to include an interview, in order to consider soft skills and the alignment of the candidate with the organisation culture, together with his or her technical skills.

\subsection{The EASME A.2 unit}

The Executive Agency for Small and Medium-sized Enterprises (EASME) was set up by the European Commission in 2014 to manage several EU programmes on its behalf in the fields of SME support \& innovation, environment, climate action, energy and maritime affairs.

At the time of creation of the agency, Bernd Reichert was appointed as the Head of the A.2 unit, responsible for the management of one of the SME instruments, the accelerator program for innovative small companies in Europe.

Having to set up a completely new unit from scratch, Reichert decided to implement a participatory management approach, using Laloux's Teal organisations framework as a reference. This implied moving from a hierarchical culture towards a culture of self-management, based on trust and freedom, where people are considered to be best positioned to know the most appropriate time and place to work, and are empowered to make decisions by themselves. With the priority on delivering the work more than discerning where the person is, unit members were allowed as much flexitime and teleworking as they wished.

The participatory management was combined with a continuous improvement programme, with people continuously examining their working procedures and processes to identify areas for efficiency gains and trying to improve them. This programme involved new practices in three different areas: process improvement, personal efficiency, and organisational development.

The process improvement practices aimed to reengineer the core business processes and increase the unit's performance. Among these practices, the most successful were the establishment of measurable project goals and workloads, the systematic communication with the client companies in order to detect which services they find useful and which not, and the assessment of the improvement initiatives by using a benefit-effort matrix.
Regarding personal efficiency, the new practices involved changing the way meetings where run, avoiding formal meetings called by the manager, and getting together only when team members felt there was something that needed to be discussed within the group. They also improved the way information was stored, how e-mails were managed, avoiding using them for general information purposes, and the way they collaborated in common projects.

Regarding organisational development, they worked on fostering self-organisation and autonomous decision making, with no formal job descriptions but the expectation for team members to learn about the full range of activities of the unit and find the roles that suit them best.

Thanks to this continuous improvement framework, the unit was able to reduce the time to sign the grant in the business accelerator programme in more than a half, allowing beneficiary companies to get support earlier.

An important part of the culture that Reichert tried to implement in EASME A.2 was related to personal development, investing in internal and external coaching, and giving people the freedom to develop themselves in areas that were not directly related to their work in the unit, according to their interests, even if this could lead them to leave the unit one day to move into an outside position closer to their aspirations. In that sense, training courses on any subject (within the training catalogue of the organisation, but also accessible through external training) were available for all colleagues, regardless of their roles at the time, and they were able to attend them once measures to ensure business continuity during their absence were agreed with the team.

Connected to the personal development, the unit also paid attention to the wholeness dimension in the Teal organisations' framework, offering different opportunities to increase the well-being of its staff, like meditation and yoga classes. In that sense, they introduced daily self-satisfaction surveys a as tool to collect feedback from the teams about their happiness at work.

As the unit did not previously exist, incorporating colleagues that would perform well under the participatory management framework was of great importance, so recruitment proved to be a challenge. Even though the unit was constraint by the Staff Regulations that rule how Human Resources (HR) processes are managed in the EU administration, it was able to introduce some changes in order to give more participation to the team in the recruitment process. New recruits had to go formally through a panel like in the usual procedure, but they were also interviewed by the team to check their fitness to the unit culture, especially with regards to their views on self-management. 


\subsection{The European Court of Auditors}

In order to be able to anticipate and respond to the challenges of the quickly changing social, political and economic environment of the EU, the European Court of Auditors decided in March 2014 to reorganise the way it worked through the implementation of a reform programme.

The main goal of this reform was to increase the relevance of the institution in improving EU accountability, by increasing its capabilities to deliver audit products. To do so, the reform included actions covering six main elements:

1. Restructuring of the Court to become a task-based organisation. This implied putting in place mechanisms for assigning resources rapidly and flexibly to the most relevant tasks. To do so, the Court moved from an organisation based on audit units, responsible for a specific audit domain, to a Courtwide pool of resources assigned to the Chambers. In practice, this meant the extinction of the unit and the function of Head of Unit, and its replacement by temporary audit teams, composed by auditors and support staff coming from the pool, and led by a Head of Task.

2. Optimisation of the audit processes. This implied adopting a set of measures to deliver reports quicker and to provide key stakeholders with high-quality information, such as: use of quick special reports with lighter procedures when feasible and necessary; shorter preparatory works for audit assignments; enhancement of the audit planning documents to focus on core issues; replacement of the Statement of Preliminary Findings with shorter, fewer, and more factual management letters; encouragement of the use of electronic communications; shorter procedures for clearing findings with the auditee; and a redesigned Annual Report.

3. Implementation of a strategy for communication and relations with stakeholders. Starting with the designation of a spokesperson and the creation of a communication and institutional relations unit, the strategy included measures to improve external and internal communication (acting on publications, Internet and Intranet sites, stakeholders' databases, corporate visual identity, etc.) with special focus on introducing mechanisms for collecting feedback from stakeholders to define the audit programme.

4. Update of the governance framework. This included the modification of the Rules of Procedures and Implementing Rules of the Court to reflect the changes in the organisation and the way of working, the setup of a new programming system, and the adoption a new ethical framework.

5. Renewal of the Information Technology and HR systems and tools, in order to support the desired changes. Regarding the HR system, several elements were analysed and redesigned, with views to improve motivation and professional development through variable career paths and personal growth measures: recruitment and integration of new auditors, training, performance assessment, career development and promotion, rewards and incentives, and team leadership skills.

6. Development of a comprehensive framework for knowledge management, based on a culture of creating and sharing knowledge. Taking advantage of the expertise of its staff, the Court aimed to capture, channel, and leverage this expertise through groups of policy experts. These groups were supported by knowledge management and skills inventory tools, training, and internal and external dissemination events. Moreover, knowledge creation and sharing were aligned with career development, as staff was encouraged, through recognition and rewards, to expand and develop their knowledge by moving between different subjects as they advanced in their careers.

After a transition period, the organisation started functioning under the new framework on the 1st of January 2016. From then, the Court has shown a steady progression on its performance with regards the delivery of the planned audit reports: $65 \%$ of the planned reports were delivered on time in $2017,93 \%$ in 2018 , and $100 \%$ in 2019 . 
Table 2 Summary of the findings in the four analysed cases. Organisational structure.

Table 3 Summary of the findings in the four analysed cases. Human Resources processes.

1 According to EU Staff Regulations rules.

\begin{tabular}{ll}
\hline Case & Main features regarding organisational structure \\
\hline & Organisation based on self-organising teams \\
\hline
\end{tabular}

Belgian Federal Public Service of Social Flattened structure, suppressing several layers of the hierarchy Security

Efficient meeting management practices

Employees can use part of their time to participate in innovation projects

Two parallel structures: one bureaucratic and hierarchical, linked to the legal obligations of the Conservatory (formal music teachings), the other flexible and agile, linked to music promotion as a citizens' service

Municipal Music Conservatory of Barcelona

Teachers can use part of their time to participate in the music promotion initiatives of their choice

\begin{tabular}{ll}
\hline \multirow{2}{*}{ EASME A.2 } & Based on Self-Managing Teams (SMT), composed of 5 to 12 people \\
\cline { 2 - 2 } European Court of Auditors & $\begin{array}{l}\text { Workload, backups, tasks, performance evaluation are organised on an SMT basis, not individual } \\
\text { basis }\end{array}$ \\
\hline $\begin{array}{l}\text { Defined as an agile Task-based organisation, supported by lean management and knowledge } \\
\text { sharing practices }\end{array}$ & $\begin{array}{l}\text { Suppression of units (and corresponding Heads of Unit) and assignment of staff to pools, although } \\
\text { administrative links to Chambers and Directorates remain }\end{array}$ \\
\cline { 2 - 2 } & \begin{tabular}{l} 
Flexible audit teams, with changing leading roles \\
\hline
\end{tabular} \\
\hline
\end{tabular}

\begin{tabular}{ll}
\hline Case & Main features regarding Human Resources processes \\
\hline & Flexible working hours and working places, facilitated by digitalisation \\
\cline { 2 - 2 } $\begin{array}{l}\text { Belgian Federal Public Service of Social } \\
\text { Security }\end{array}$ & Employees are assessed for their performance rather than working time \\
\cline { 2 - 2 } &
\end{tabular}

Bottom-up evaluation of managers

Training sessions proposed by at least 3 colleagues are approved and organised

Municipal Music Conservatory of Barcelona

Teachers enjoy flexible working timetable

Teachers' selection processes tailored to the culture of the organisation

Team participates in the selection process by interviewing short-listed candidates

Loose job descriptions

EASME A.2

Telework and flexitime ${ }^{1}$

The unit supports training not only related to the actual work and current function, but also to the personal interests and expectations

Integration programme for new auditors with rotation through different Chambers

Input from team members in performance assessments

Rotation based on knowledge, skills, interests, and development needs

Telework and flexitime ${ }^{1}$

Performance Recognition Awards that can be used as training credits 
Table 4 Summary of the findings in the four analysed cases. Daily practices.

\begin{tabular}{ll}
\hline Case & Main features regarding daily practices \\
\hline Working space layout linked to activity, not to hierarchy \\
\hline
\end{tabular}

No offices assigned to people (including senior management), but areas that promote concentration, creativity, and contact between colleagues

Belgian Federal Public Service of Social Decisions are made as far as possible by the employees themselves, who engage in a continuous Security process to design of the future of the organisation

The whole workforce is involved in the definition of the strategy

SPFSS values have been translated into concrete behaviours in daily practice through a participatory process

Deontology code, including guiding attitudes and values, created with the participation of employees

Parking spaces to be used by everyone, independently from the level in the hierarchy

Municipal Music Conservatory of Barcelona

Regular meditation practices open to everyone

Crystal walls and doors to foster openness and transparency

Used Laloux's framework as the guide for organisational development

All team members trained in Participatory Leadership

Interactive workshops are used in all internal and external events

EASME A.2

Internal and external coaching practices

Self-satisfaction surveys

Open offices

Colleagues are encouraged to bring their hobbies to the team

Pilot projects for introducing open office spaces

Collaboration spaces and innovation meeting rooms to support brainstorming

European Court of Auditors

Well-being initiatives self-managed by the staff

ECALAB, innovation laboratory for applying technology to auditing needs

Moving towards a 'Right to experiment' culture 
Table 5 Summary of the findings in the four analysed cases. Emergence, resilience, and sustainability.

\begin{tabular}{|c|c|}
\hline Case & Main features regarding emergence, resilience, and sustainability \\
\hline \multirow{2}{*}{$\begin{array}{l}\text { Belgian Federal Public Service of Social } \\
\text { Security }\end{array}$} & $\begin{array}{l}\text { Organisational innovation triggered in } 2006 \text { by the need to attract young people to ensure service } \\
\text { sustainability }\end{array}$ \\
\hline & $\begin{array}{l}\text { Innovation took root and has been sustained. Nowadays, SPFSS profiles itself as a modern and } \\
\text { inspiring public service, an organisation continuously evolving and aspiring to learn and be happy, } \\
\text { sexy, agile, collaborative, and responsible }\end{array}$ \\
\hline \multirow{3}{*}{$\begin{array}{l}\text { Municipal Music Conservatory of } \\
\text { Barcelona }\end{array}$} & $\begin{array}{l}\text { Innovation triggered by the appointment of a new manager after an institutional crisis in early } \\
2000 \text { 's }\end{array}$ \\
\hline & $\begin{array}{l}\text { 'Holes' in bureaucratic structure and processes were used to start experimenting with innovation } \\
\text { practices, though friction between both worlds remains }\end{array}$ \\
\hline & Change in leadership is perceived as a major concern for sustainability \\
\hline \multirow{5}{*}{ EASME A.2 } & Innovation triggered by the manager leading the unit in 2014 when the agency started \\
\hline & Tensions with other areas of the agency working in the traditional way were frequent \\
\hline & \\
\hline & Unwillingness to take responsibility by some team members seen as an obstacle to self-management \\
\hline & Sustainability under question as the manager and other key people have left the unit \\
\hline \multirow{5}{*}{ European Court of Auditors } & Innovation as part of a large reform programme implemented by 2016 \\
\hline & Triggered by the 2007 economic crisis and the need to deliver audit reports timely on new fields \\
\hline & \\
\hline & Innovation supported by a flexible interpretation of the EU Staff Regulations \\
\hline & Sustainability linked to the current reflection on the achieved results \\
\hline
\end{tabular}

Table 6 Summary of the findings in the four analysed cases. Effect on performance.

\begin{tabular}{ll}
\hline Case & Main features regarding the effect on performance \\
\hline \multirow{3}{*}{$\begin{array}{l}\text { Belgian Federal Public Service of Social } \\
\text { Security }\end{array}$} & $\begin{array}{l}\text { SPFSS attractiveness to new arrivals to Belgian public service boosted. In } 2002 \text { only } 18 \% \text { were } \\
\text { willing to work there while in } 2016 \text { it was the preferred destination with } 93 \% \text { applying to join }\end{array}$ \\
\cline { 2 - 2 } & $\begin{array}{l}\text { Consistent two-digit productivity increases (23\% in 2009, the first year of transformation, } 11 \% \text { in } \\
2010,15 \% \text { in 2011) }\end{array}$ \\
\hline \multirow{3}{*}{$\begin{array}{l}\text { Municipal Music Conservatory of } \\
\text { Barcelona }\end{array}$} & Snnovation allowed to revitalise a declining institution \\
\cline { 2 - 2 } & New motivation sources for teachers were created \\
\cline { 2 - 2 } & $\begin{array}{l}\text { Music brought closer to citizens by means of activities like open courses, free concerts, or the } \\
\text { Conservatory online radio }\end{array}$ \\
\hline EASME A.2 & $\begin{array}{l}\text { Organisational innovation allowed for a significant improvement in one of the main processes of the } \\
\text { unit (grants conceded to SMEs), as time to grant was reduced from } 8 \text { to } 3 \text { months }\end{array}$ \\
\hline \multirow{3}{*}{ European Court of Auditors } & The goal of reducing staff numbers by $5 \%$ was achieved \\
\hline & Time to deliver audit reports has been reduced \\
\cline { 2 - 2 } & \\
\hline
\end{tabular}




\section{Discussion}

When compared to each other, the four cases studied present evident differences in the following aspects:

- Change width: In three of the cases (SPFSS, Music Conservatory and Court of Auditors), innovations affected the whole organisation, while in one of them (EASME.A2) the innovations were introduced only in a small part of it (one of the 8 units of the agency). Also, the number of people affected by the organisational change in the four cases varies; while the staff in the Music Conservatory and EASME.A2 amounts to about 80 people, the staff in the SPFSS and the Court of Auditors is approximately ten times higher (around 700 in the case of SPFSS and 830 in the case of the Court of Auditors).

- Change comprehensiveness: Considering to which extent the three dimensions of change analysed in the research (organisational structure, human resources processes and daily practices) were affected by the organisational transformation, SPFSS seems to have introduced a more balanced change, with profound innovations in all three areas. Innovations in EASME.A2 also affected consistently the three areas, although they were probably not so ground-breaking as in the case of SPFSS. In the case of the Music Conservatory and the Court of Auditors, however, main innovations were more focused in one area (daily practices in the Music Conservatory, organisational structure in the Court of Auditors) than the rest.

- Change leadership: In the case of EASME.A2 and the Music Conservatory, organisational innovation started mainly because of the vision and commitment of a single individual, who led the implementation of the intended changes. In the case of SPFSS and the Court of Auditors, even though this might have been the case too in the very beginning, change was quickly adopted and supported by the management team, so leadership remained more distributed.

- $\quad$ Focus on Teal breakthroughs: Self-organisation seems to be the only trait of Teal organisations appearing in the four cases, although with different levels of intensity: higher in SPFSS, with the removal of several levels of the hierarchy, and lower in the Music Conservatory, with self-organisation occurring only in part of its activities, being EASME.A2 and the Court of Auditors somewhere in between. Wholeness is also present somehow in the daily practices of the Music Conservatory and EASME.A2, and maybe in SPFSS, but does not seem to be a guiding principle for the Court of Auditors. As for the evolutionary purpose, it can be recognised in SPFSS with the participatory practices to define strategy and with the behaviours implementing its values, as well as in the Music Conservatory with the preparation of the deontology code.

Despite these differences, some common patterns emerge: the existence of a activating event (creation of a new organisation, arrival of a new manager, need to respond to an internal or external crisis) that triggers the organisational change, the openness and commitment of leaders to experiment new ways of working as a driver for improvement, and a pragmatic and opportunistic approach to exploit the gaps left by rules and procedures for introducing new practices.

The sustainability of the innovations is not, however, guaranteed; the dependency on the leaders that launched and support them, the resistance of those members not convinced by the new ways, and the rejection to what is different, due to the strangeness of the new practices, that may appear in other areas of the organisation or in key decision makers, can be important threats to their continuity.

As for organisational performance, although measuring performance in public sector remains a difficult and disputed topic, there is some evidence of the positive effects of the organisational innovations on some performance indicators of the organisations studied in the research.

\section{Conclusion}

Even though the sample of cases is too small to draw general conclusions, our findings show that innovation in organisational practices in the public sector is not only possible, but it is happening. While changing human resources processes and organisational structures is difficult due to the constraints imposed by the political context and the regulatory framework, there is some flexibility in daily practices for introducing new ways of working that may have a positive impact on the functioning of the organisation.

However, the scarcity of known experiences prevents from assessing to which extent the organisational innovations examined in this research are representative of the changes undergoing in the public sector. In that sense, further investigation is needed, not only to identify innovative practices in other public organisations, but to analyse if these practices are able to take root and sustain organisational improvement, or, on the contrary, are swept away by the strong forces of bureaucratic conservatism.

As organisational innovation can be an important lever for public sector reforms aimed to increase its performance, future research should also address in more depth the actual effect on performance of these organisational innovations, looking for supplementary evidence of the improvements after their introduction. 
Additionally, the development of an experimental model based on the findings of this research, to be verified by means of a quantitative analysis, could be another relevant line of investigation for future work.

\section{References}

ANDERSON, P. (1990) "Complexity Theory and Organization Science". Organization Science, 10, pp. 216-232. https://www.jstor.org/stable/2640328

BECK, D. and COWAN, C. (1996). Spiral Dynamics: Mastering Values, Leadership and Change; Malden: Blackwell Publishers Inc.

BOHÓRQUEZARÉVALO, L.E. and ESPINOSA, A. (2015). "Theoretical approaches to managing complexity in organizations: A comparative analysis". Estudios Gerenciales, 31, pp. 20-29. https://doi.org/10.1016/j. estger.2014.10.001

BOYNE, G.A. (2003). "Sources of Public Service Improvement: A Critical Review and Research Agenda". Journal of Public Administration Research and Theory, 13, pp. 367-394. https://doi.org/10.1093/jopart/mug027

DANEKE, G.A. (1990). “A Science of Public Administration?" Public Administration Review, 50, pp. 383-392. https://doi.org/10.2307/976620

DE BRUIN, R.; PRIETO TOVAR, S. and PELLAND, D. (2017). Twenty-first Century Leadership for EU Institutions, pp. 71-80, Newcastle upon Tyne: Cambridge Scholars Publishing.

EISENHARDT, K.M. (1989). "Building Theories from Case Study Research". Academy of Management Review, 14, pp. 532-550. https://doi.org/10.5465/amr.1989.4308385

EISENHARDT, K.M. and GRAEBNER M.E. (2007). "Theory building from cases: Opportunities and challenges". Academy of Management Journal, 50, pp. 25-32. https://doi.org/10.5465/AMJ.2007.24160888

EPPEL, E.A. and RHODES, M.L. (2018). "Complexity theory and public management: a 'becoming' field”. Public Management Review, 20, pp. 949-959. https://doi.org/10.1080/14719037.2017.1364414

EUROPEAN COMMISSION. (2017). Quality of Public Administration - A toolbox for practitioners. Theme 4, Organisations - managing performance, quality and people. https://doi.org/10.2767/325126
EUROPEAN COURT OF AUDITORS. (2015). "The ECA reform programme". Journal of the European Court of Auditors, 6, pp. 9-11.

GEYER, R. and CAIRNEY, P. (Eds.). (2015) Handbook on Complexity and Public Policy. Cheltenham: Edward Elgar Publishing Limited. https://doi. org/10.4337/9781782549529

GÓMEZ MUÑOZ, C.F. and SERRANO CALLE, S. (2018). "La organización evolutiva como marco de referencia para la transformación de las Administraciones Públicas". Economía Industrial, 408, pp. 63-75.

GRAVES, C. W. (1970). "Levels of existence: an open system theory of values". Journal of Humanistic Psychology, 10, pp. 131-155.

HOLLAND, J.H. (2006). "Studying complex adaptive systems". Journal of Systems Science and Complexity, 19, pp. 1-8. https://doi.org/10.1007/s11424-006-0001-z

KERR, P. (2002) "Saved from Extinction: Evolutionary Theorising, Politics and the State". The British Journal of Politics and International Relations, 4, pp. 330-358. https://doi.org/10.1111/1467-856x.t01-1-00008

KLIJN, E.H. (2008) "Complexity theory and public administration: What's new?" Public Management Review, 10, pp. 299-317. https://doi. org/10.1080/14719030802002675

LALOUX, F. (2014). Reinventing Organizations: A Guide to Creating Organizations Inspired by the Next Stage of Human Consciousness; Brussels: Nelson Parker.

LEE, M. Y. and EDMONDSON, A. C. (2017). "Selfmanaging organizations: Exploring the limits of less-hierarchical organizing". Research in Organizational Behavior, 37, pp. 35-58. https://doi.org/10.1016/j. riob.2017.10.002

LEVIN, S.A. (1998). Ecosystems and the biosphere as complex adaptive systems. Ecosystems, 1, pp. 431-436. https://doi.org/10.1007/s100219900037

LEVIN, S.A. (2003). “Complex adaptive systems: Exploring the known, the unknown and the unknowable". Bulletin of the American Mathematical Society, 40, pp. 3-19. https://doi.org/10.1090/S0273-0979-02-00965-5

LUHMANN, N. (1995) Social Systems; Stanford: Stanford University Press.

MARTI, D. and DONCEL CARRILLO M.S. (2018). "La música como propósito evolutivo". Economía Industrial, 408, pp. 31-40. 
MCKELVEY, B. (1997). "Quasi-Natural Organization Science”. Organization Science, 8, pp. 352-380.

https://www.jstor.org/stable/2635209

MITLETON-KELLY, E. (2003). “Ten Principles of Complexity and Enabling Infrastructures". In: MitletonKelly, E. (Ed.), Complex Systems and Evolutionary Perspectives of Organisations: The Application of Complexity Theory to Organisations, pp. 23-50, Bingley: Emerald Group Publishing.

OECD. (2017) Working with Change: Systems approaches to public sector challenges. https://doi.org/10.1787/9789264279865-en

SEIDL, D. and MORMANN, H. (2015). "Niklas Luhmann as Organization Theorist". In: Adler, P.; du Gay, P.; Morgan, G. and Reed, M. (Eds.), Oxford Handbook of Sociology, Social Theory and Organization Studies: Contemporary Currents, pp. 125-157, Oxford: Oxford University Press. https://doi.org/10.1093/ oxfordhb/9780199671083.013.0007

SEMENTELLI, A. (2007). "Distortions of Progress". Administration \& Society, 39, pp. 740-760, https://doi. org/10.1177/0095399707304432

SPF SECURITÉ SOCIALE. Website of the Belgian SPF Securité Sociale. Available online: https://socialsecurity. belgium.be/fr (accessed on 9 February 2020).

STACEY, R. D. (1995). The science of complexity: An alternative perspective for strategic change processes. Strategic Management Journal, 16, pp. 477495. https://doi.org/10.1002/smj.4250160606
STENVALL, J. and VIRTANEN, P. (2017). "Intelligent Public Organisations". Public Organization Review, 17, pp. 195-209. https://doi.org/10.1007/s11115-015-03311

TEISMAN, G.; VAN BUUREN, A. and GERRITS, L. (Eds.). (2009). Managing Complex Governance Systems. New York: Routledge. https://doi. org/10.4324/9780203866160

VAN MASSENHOVE, F. Shift or shrink: Frank Van Massenhove at TEDxGhent. Available online: https://www.youtube.com/watch?v=-ZgJajcyaow (accessed on 2 February 2020).

VOGEL, R. (2014). "What Happened to the Public Organization? A Bibliometric Analysis of Public Administration and Organization Studies". The American Review of Public Administration, 44, pp. 383-408. https://doi.org/10.1177/0275074012470867

WILBER, K. (2005). "Introduction to integral theory and practice". Journal of Integral Theory and Practice, 1, pp. $1-38$.

WYRZYKOWSKA, B. (2019). "Teal Organizations: Literature Review and Future Research Directions". Central European Management Journal, 27, pp. 124141. https://doi.org/10.7206/cemj.2658-0845.12 